\title{
Program for Solar Water Heating Systems Based on the F-Chart Method
}

Félix do Rego Barros ${ }^{1}$, Adriano Gatto Lemos ${ }^{2}$, Sildenir Alves Ribeiro ${ }^{1}$ and Manoel Antonio da Fonseca Costa Filho $^{3}$

1. Coordination of Industrial Automation, CEFET (Federal Center of Technological Education), Rio de Janeiro 20785-902, Brazil

2. Coordination of Automotive Maintenance, CEFET (Federal Center of Technological Education), Rio de Janeiro 20785-902, Brazil

3. Department of Mechanical Engineering, UERJ (State University of Rio de Janeiro), Rio de Janeiro 20940-200, Brazil

Received: March 31, 2014 / Accepted: April 15, 2014 / Published: September 25, 2014.

\begin{abstract}
This paper aims at presenting an application developed in Java for optimizing the design of centralized solar water heating systems with forced circulation, based on the f-chart method. The program uses data from the Brazilian Solar Atlas, performance data of flat plate collectors and thermal reservoirs from the standardized tests run within the Brazilian Labeling Program, and values of water consumption of appliances defined by the ABNT. The program finds the inclination of the collector that maximizes the annual solar fraction, or for the winter, and enables the use of arrays in series and parallel collectors. From the investment costs and O \& $\mathrm{M}$ (operations and maintenance) of solar heating systems, the program carries out economical analysis using classical parameters as net present value, discounted payback and internal rate of return. The program was validated through examples from the book of Duffie \& Beckman and also by comparison with the results from a project developed at UFRGS, having obtained good agreement.
\end{abstract}

Key words: Solar water heating, f-chart method, solar collectors.

\section{Introduction}

In Brazil, the widespread use of electrical showerheads that provide hot water for domestic consumption contributes to a load curve that peaks in the early evening, imposing a considerable burden to generation, transmission, and distribution utilities. On average, over $73 \%$ of Brazilian households use these 3-8 kW electrical resistance showerheads.

In some of the more temperate climate regions in the south of the country, where most of the Brazilian population is concentrated, electrical showers are present in over $90 \%$ of residential buildings. For the residential consumer, while these high-power heating devices are the least-cost investment alternative, they

Corresponding author: Félix do Rego Barros, M.Sc., assistant professor, research fields: solar energy, industrial automation, electrical and mechanical engineering for industrial development. E-mail: felix.barros@cefet-rj.br. lead to high running energy costs.

Furthermore, due to their very low load factor (typically below 2\%), each of these high-power showerheads results in considerably low return on the high investment costs in terms of infrastructure for the electricity sector [2].

Additionally, typical utilization times coincide with and contribute to the electrical power demand peaks in Brazil, rendering these low-cost, high-power electrical devices a high-cost consumer for the electrical system to cater for [3].

According to the Eletrobra's national utility [4], electrical showers are responsible about $60 \%$ of the residential electrical load at peak load hours [2].

The solar water heating is the most attractive option for shaving this electrical load peak. The Brazilian solar radiation resource is one of the largest in the world [1] which is available all over the country 
throughout all seasons. But the wide-spread of solar water heating systems is constraint by high investment costs and the lack of knowledge of economical performance. Computational tools allow predicting the thermal performance of solar water heating systems which are a potential way to proportionate conditions to the designers to precisely estimate the payback period and contributing to increase the solar water heating [12].

This paper presents a software for optimizing the design of solar water heating systems developed based on a previous work $[13,19]$. The main advantage of the current proposal is that the software carries out thermal and economical analysis using technical data from equipments commercially available in Brazil. Additionally, typical Brazilian domestic hot water consumption data are taken into account, including design specifications from Brazilian standards.

Only water heating systems with forced circulation using flat plate solar collectors can be designed. All the constraints from the f-chart method were considered during software development and must be known by the software users.

The f-chart method offers a uncial for the designers and field engineers, but it has many limitations, such as the specific design configuration, system size and design parameter restrictions, as well as the lack of flexibility to cover any hourly load demand profile [14]. But the Brazilian domestic hot water consumption profiles adjust well to these constraints, since the consumption is concentrated in early evening, after sunshine.

\section{Computational Tools for Solar Heating System Performance Simulation and Design}

It is widely recognized that the most accurate and complete solar design tool currently available is the TRNSYS computer simulation model, developed in Ref. [18]. This tool has been very much enriched and refined and its validity and accuracy have been repeatedly confirmed since then. It is very appropriate as an analysis and research tool and there are many TRNSYS simulations of solar water heating systems available in Refs. [5-7]. Although it is very appropriate for researching purposes, its complexity and required expertise make it difficult to be used by the field engineers.

The f-chart is a simplified design method of solar space and water heating systems for residences [18]. It is a simple graphical method requiring only monthly average meteorological data for estimating the long-term thermal performance of solar heating systems, suitable for engineers and architects.

The SAM (solar advisor model) (www.nrel.gov/docs/fy12osti/49150.pdf) developed by the NREL (National Renewable Energy Laboratory) is a program for calculating and comparing cost and performance of solar power systems. It is a framework that contains some modules TRNSYS responsible for calculations and a graphical interface where the systems are configured to be calculated in a more simplified way than in TRNSYS.

RETScreen is an Excel-based clean energy project analysis software tool that helps decision makers quickly and inexpensively determine the technical and financial viability of potential renewable energy, energy efficiency and cogeneration projects. RETScreen Plus is a Windows-based energy management software tool that allows project owners to easily verify the ongoing energy performance of their facilities [16]. Both computational tools encompass solar energy projects.

In the University of the Rio de Janeiro State, a thermal performance simulation program of solar water heating systems $[12,15,23]$ was developed. The implemented model computes the mass and energy balances in the thermal tank in each time step along a simulation interval, typically an hour throughout a year. Its input data values are from a typical meteorological year of a chosen location and the hot water load. The system components are the hot water storage tank and the solar collector. It was 
validated through comparisons with results from TRNSYS simulations.

\section{Solar Radiation Model}

The solar radiation is splitted in the beam and diffuses components. Sky models are mathematical representation of the diffuse radiation. The current software uses the isotropic diffuse model developed by Liu and Jordan in 1963 APUD [8]. The radiation on the tilted surface is considered to include three components: the beam radiation $\left(I_{b}\right)$, the isotropic diffuse radiation from the sky $\left(I_{d}\right)$, and solar radiation reflected diffusively from the ground $\left(I_{\rho g}\right)$. One tilted surface with inclination $\beta$ to the horizontal has a view factor to the sky $F_{c^{-s}}=(1+\cos \beta) / 2$ and a view factor to ground $F_{c-g}=(1-\cos \beta) / 2$. The total incident radiation can be written as [8]:

$$
I_{T}=I_{b} \cdot R_{b}+I_{d} \cdot\left(\frac{1+\cos \beta}{2}\right)+I_{\rho g} \cdot\left(\frac{1-\cos \beta}{2}\right)
$$

where, $R_{b}$ is the ratio of beam radiation on the tilted surface to that on a horizontal surface and is defined as:

$$
R_{b}=\frac{\cos \theta}{\cos \theta_{z}}
$$

where, $\theta$ is the angle of incidence and $\theta_{z}$ is the zenith angle.

The software utilizes an optimization routine for encountering the inclination angle $(\beta)$ that maximizes the solar radiation incident on the collector surface taking in account all months or optionally only the winter months, through maximizing $R_{b}$ in Eq. (3).

$R_{B}=\frac{\left(\frac{\pi}{180}\right) \cdot \omega_{S}^{\prime} \cdot \operatorname{sen}(\phi+\beta) \cdot \operatorname{sen} \delta+\operatorname{sen} \omega_{S}^{\prime} \cdot \cos \delta \cdot \cos (\phi+\beta)}{\cos \phi \cdot \cos \delta \cdot \operatorname{sen} \omega_{S}+\left(\frac{\pi}{180}\right) \cdot \omega_{S} \cdot \operatorname{sen} \phi \cdot \operatorname{sen} \delta}$

where, $\quad \omega_{S}^{\prime}=\min \left[\begin{array}{l}\cos ^{-1}(-\tan \phi \cdot \tan \delta) \\ \cos ^{-1}(-\tan (\phi+\beta) \cdot \tan \delta)\end{array}\right]$

$\delta, \phi$ and $\omega_{s}$ are the solar declination angle, the latitude and the sunset (or sunrise) hour angle, respectively.

Eq. (3) is valid for surfaces in the southern hemisphere sloped toward the equator. For sites in the northern hemisphere, the equation is similar and it was omitted here due to space limitation. The numerator of this equation is the extraterrestrial radiation on the tilted surface and the denominator is that on the horizontal surface.

The monthly average integrated daily extraterrestrial radiation $\bar{H}_{0}$ is calculated in Eq. (4):

$$
\begin{gathered}
\bar{H}_{0}=\frac{24.3600 \cdot G s c}{\pi}\left(1+0.033 \cdot \cos \left(\frac{2 \pi d}{365}\right)\right) \\
\left(\cos \emptyset \cdot \cos \delta \cdot \operatorname{sen} \omega_{S}+\omega_{S} \operatorname{sen} \emptyset \cdot \operatorname{sen} \delta\right)
\end{gathered}
$$

where, $G_{S C}$ is the solar constant and $d$ is the day of the year, from 1 to 365 . For latitudes in the range +60 to -60 , it can be calculated using $n$ and $\delta$ for the mean day of the month, as described in Ref. [8],

$$
\bar{K}_{T}=\frac{\bar{H}}{\bar{H}_{0}}
$$

The software requires monthly average values of the integrated daily radiation on the tilted surface $\overline{H_{r}}$. They are calculated in Eq. (6) through a summation procedure similar to Eq. (1), where, $\bar{H}$ is the total radiation and the subscripts $d$ and $\rho g$ refer to the diffuse and ground-reflected components.

$$
\bar{H}_{T}=\bar{H}\left(1-\frac{\bar{H}_{d}}{\bar{H}}\right) R_{B}+\bar{H}_{d}\left(\frac{1+\cos \beta}{2}\right)+\bar{H}_{\rho g}\left(\frac{1-\cos \beta}{2}\right)
$$

The diffuse component is related with the total radiation as proposed by Collares-Pereira a Rabl in 1979 APUD [8]:

$$
\begin{aligned}
& \frac{\bar{H}_{4}}{\bar{H}}=0.775+0.00606 \cdot\left(\omega_{2}-90\right)-[0.505+ \\
& \left.0.00455 \cdot\left(\omega_{2}-90\right)\right] \cdot \cos \left(115 \bar{k}_{T}-103\right)
\end{aligned}
$$

\section{Component of Physical Models}

The model assumptions are:

- The thermal tank containing the stored hot water is treated by the fully-mixed sensible heat model, i.e., there is no internal thermal stratification;

- There is a controller that turns the pump on only if there is a minimum temperature difference and a 
useful energy output from the collector to justify it;

- The solar collector model uses a linear form of the collector efficiency and does not include incidence angle modifier for correction of the inclination angle;

- There is no intermediate heat exchanger since the water that circulates in the solar collector and is stored and consumed is the same.

The useful output heat flux from the solar collector is the difference between the thermal power absorbed by the collector plate and heat losses to the environment, expressed based on the Hottel-Williers equation as described in Ref. [8]:

$$
Q_{u}=A_{c} \cdot F_{R} \cdot\left[G_{T} \cdot(\tau \cdot \alpha)-U_{L} \cdot\left(T_{i}-T_{a}\right)\right]
$$

where, $F_{R}$ is the heat removal factor defined as the ratio between the actual useful energy gain of a collector and the useful gain if the whole collector surface were at the fluid inlet temperature. $(\tau \alpha)$ is the product of the coverage transmittance by the collector plate absorbance, $G_{T}$ is the incident irradiance on the collector. $U_{L}$ is the overall heat loss coefficient, which includes all losses from the collector. $T_{i}$ and $T_{a}$ are the water temperature at collector inlet and the environment temperature, respectively. $A_{c}$ is the total area of the collector.

As mentioned above, operation of a forced-circulation collector will not be carried out when $Q \mathrm{u}<0$. The values of $F_{R} \cdot(\tau \alpha)$ and $F_{R} \cdot U_{L}$ express the collector efficiency linear behavior and are obtained from standardized tests in Refs. [9-11], available in Brazil from the PBE (Brazilian Labeling Program) coordinated by the INMETRO (National Institute of Metrology, Standardization and Industrial Quality). The software adjusts the values of these parameters when the flow rate utilization is in the range between $25 \%$ above and $25 \%$ below the flow rate of the standardized test.

The software allows both series and parallel connections in arrays of solar collectors. In series arrays, the decrease in thermal performance of the second (and subsequent) module is considered as described in Ref. [8]:

$$
\left.F_{R}(\tau \alpha)=F_{R 1}(\tau \alpha)\right)_{1}\left[\frac{1-(1-K)^{N}}{N K}\right]
$$

and

$$
F_{R} U_{L}=F_{R 1} U_{L_{1}}\left[\frac{1-(1-K)^{N}}{N K}\right]
$$

where, $N$ is the number of collectors in series and $K$ is given by:

$$
K=\frac{A F_{R} U_{L}}{\dot{m} C_{P}}
$$

the heat loss through the storage tank walls is written by:

$$
L_{P}=(U \cdot A) \cdot\left(T-T_{a}\right)
$$

where, $A$ is the corresponding area, $T_{a}$ is the environment temperature and $U$ is the global heat transfer coefficient, which includes all thermal losses. This last parameter is obtained from standardized tests prescribed in Ref. [9], also within the PBE.

The storage tank volume is calculated from the hot water consumption through the summation of the products of number of users, usage flow rate and utilization time. Since thermal reservoirs are standardized, the software indicates the standardized volume immediately above. Both the adopted appliance usage flow rates and utilization times are those from the Brazilian standards.

The heat losses through the pipeline are calculated from the correlation proposed in Ref. [20] for forced convective heat transfer with Peclet number greater than 0.2:

$$
N u=0.3+\frac{0.62 \operatorname{Re}^{1 / 2} \operatorname{Pr}^{1 / 3}}{\left[1+(0.4 / P r)^{2 / 3}\right]^{C 1}}\left[1+(D)^{A}\right]^{B}
$$

where, the coefficients $A, B, C 1$ and $D$ are related to $R e$ (reynolds number) ranges and $P r$ is the Prandtl number.

The natural convection, as suggested in Ref. [21], is the predominant heat transfer mechanism when the $G r$ (Grashof) number divided by the square of the Reynolds number is greater than 1.0. In this case, the 
software uses the correlation proposed in Ref. [20], valid for $10^{-5}<G r$ and $\operatorname{Pr}<10^{12}$.

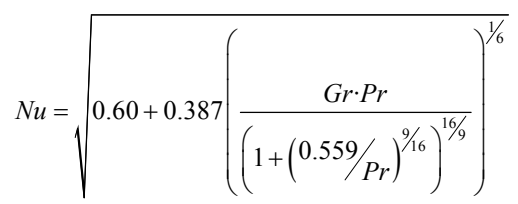

The pipe surface temperature $T_{(x)}$ varies with the position $(x)$ along the pipe length $(l)$ and can be expressed as [22]:

$$
T_{(x)}=T_{\text {air }}+\left(T_{(x 0)}-T_{\text {air }}\right) \cdot e^{\frac{-4 x}{\rho \cdot c \cdot v_{w} \cdot \pi \cdot d l^{2} \cdot l \cdot R_{T o t}}}
$$

where, $T_{\text {air }}, d_{i}, v_{w}, \rho, c, R_{\text {Tot }}$ and $x_{0}$ are the air temperature, the pipe inside diameter, the water velocity, water density, water specific heat and a pipe location where the surface temperature is known, respectively. The total pipeline heat losses $\left(q_{\text {pipe }}\right)$ are determined by the summation as

$$
q_{\text {pipe }}=\sum_{x=0}^{x=L} h_{c} \cdot A \cdot\left(T_{(x)}-T_{\text {air }}\right)
$$

\section{Climatic Data of Other Calculations}

Monthly average daily temperatures are obtained from the Brazilian Meteorological Station Data for the considered site available in the web.

The monthly average water mains temperatures $\left(T_{\text {mains }}\right)$ are approached by a fixed amount of degrees Celsius below the correspondent environmental temperature.

The mensal hot water load $(L)$ is calculated in Eq. (16) considering the bath water temperature $\left(T_{\text {bath }}\right)$ :

$$
L=\rho V c\left(T_{\text {bath }}-T_{\text {mains }}\right)
$$

from the investment costs and $\mathrm{O} \& \mathrm{M}$ (operations and maintenance) of solar heating systems, the program carries out economical analysis using classical parameters as net present value, discounted payback and internal rate of return. The detailed economical analysis is out of the scope of this paper.

\section{The F-Chart Method}

The f-chart method has the following configuration constraints:

- The water consumption is carried out only at evening;

- The ratio of the collector area $\left(\mathrm{m}^{2}\right)$ to the storage tank volume (L) must be within the range from 37.5 to 300 ;

- The ranges of the design parameters are shown in Table 1 [8].

The solar fraction $(f)$ of the monthly total load supplied by the solar water heating system is given as a function of two parameters ( $X$ and $Y$ ) as described in Ref. [8]:

$$
f=1.029 Y-0.065 X-0.245 Y^{2}+0.0018 X^{2}+
$$
$0.0215 Y^{3}$

$$
\begin{gathered}
X=\frac{A c F{ }_{R} U_{L}(\text { Tref }-\bar{T} a) \Delta t}{L} \\
Y=\frac{A c F{ }^{\prime} R(\tau \alpha) \bar{H}_{T} N}{L}
\end{gathered}
$$

where, $A c$ is the collection area $\left(\mathrm{m}^{2}\right), \Delta t$ is the total number of seconds in the month, $T_{a}$ is the monthly average ambient temperature $\left({ }^{\circ} \mathrm{C}\right), \quad T_{\text {ref }}$ is an empirically derived reference temperature $\left(100{ }^{\circ} \mathrm{C}\right), L$ is the monthly total hot water load (J), $H_{T}=$ monthy average daily radiation incident on the collector surface per unit area $\left(\mathrm{J} / \mathrm{m}^{2}\right), N=$ days in month, $(\tau a)=$ monthly average transmittance-absorptance.

\section{Software Description}

\subsection{Conceptual Modeling Software}

The conceptual model helps the programmer in the representation of the problem domain and consequently the functions of software illustrating their associations, compositions, specializations and attributes through abstraction and decomposition of the problem domain.

Table 1 Ranges of design parameters used in the development of the f-chart for liquid systems.

\begin{tabular}{lllll}
\hline 0.6 & $<$ & $(\tau \alpha)_{n}$ & $<$ & 0.9 \\
\hline 5 & $<$ & $F_{R}{ }^{A} c$ & $<$ & $120 \mathrm{~m}^{2}$ \\
2.1 & $<$ & $U_{L}$ & $<$ & $8.3 \mathrm{~W} / \mathrm{m}^{2} \mathrm{C}$ \\
30 & $<$ & $\beta$ & $<$ & $90^{\circ}$ \\
83 & $<$ & $(U A) h$ & $<$ & 0.9 \\
\hline
\end{tabular}


In this work, specifically, three diagrams were built: use case diagrams and sequence diagram of activities in Fig. 1 and class diagram in Fig. 2. These diagrams are sufficient to model the problem and represent the problem domain.

\subsection{Conceptual Model of the Database}

The database is a computational environment used not only for storage, but also for extraction and analysis including statistics of all stored data in the repository. The DBDesign and the MySQL were used as a tool for data modeling and as a repository, respectively. The option for this tool is justified by the fact that both DBDesign and MySQL are free and also they are fully integrated. The model shown in Fig. 3 represents the set of tables and their relationships in the database. Each table has an own set of attributes that will index the data stored.

\subsection{Coding System}

Table 2 contains the main Java classes developed.
The Java programming language was chosen because it has some advantages such as:

(1) Portability: Java can run on any platform or device that has a Java interpreter, and that has been especially compiled for the system to be used;

(2) Object orientation: Java is a fully object-oriented, which allows codes reuse (packages, classes, etc.);

(3) High performance: Java language supports multiple high-performance features such as multithreading, build just-in-time and the use of native code.

\subsection{Graphical Interface}

The graphical user interface of the software was developed in order to facilitate and turn practical the interaction with the user. Due to the complexity of some functions of the system, an interface consisting of tabs that allows a more dynamic and interactive navigation during use was bulit. Each window function represents a software graph.

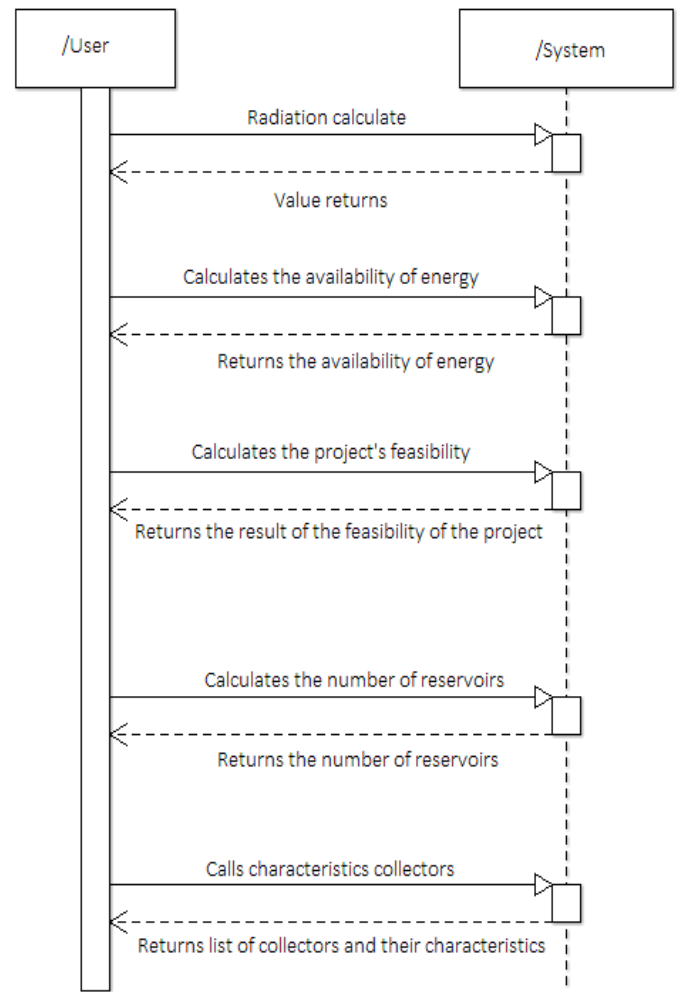

(b)

Fig. 1 (a) Use case diagram and (b) activity diagram. 


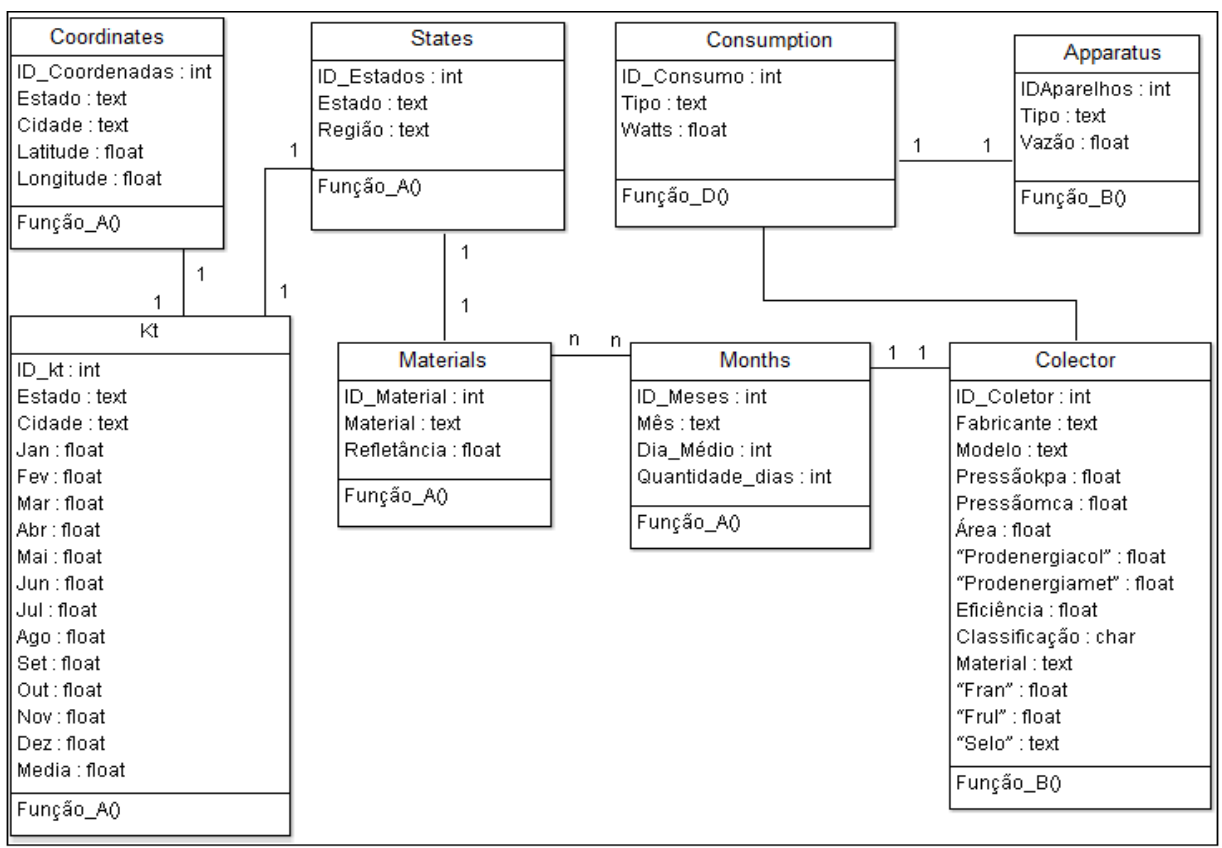

Fig. 2 Class diagram.

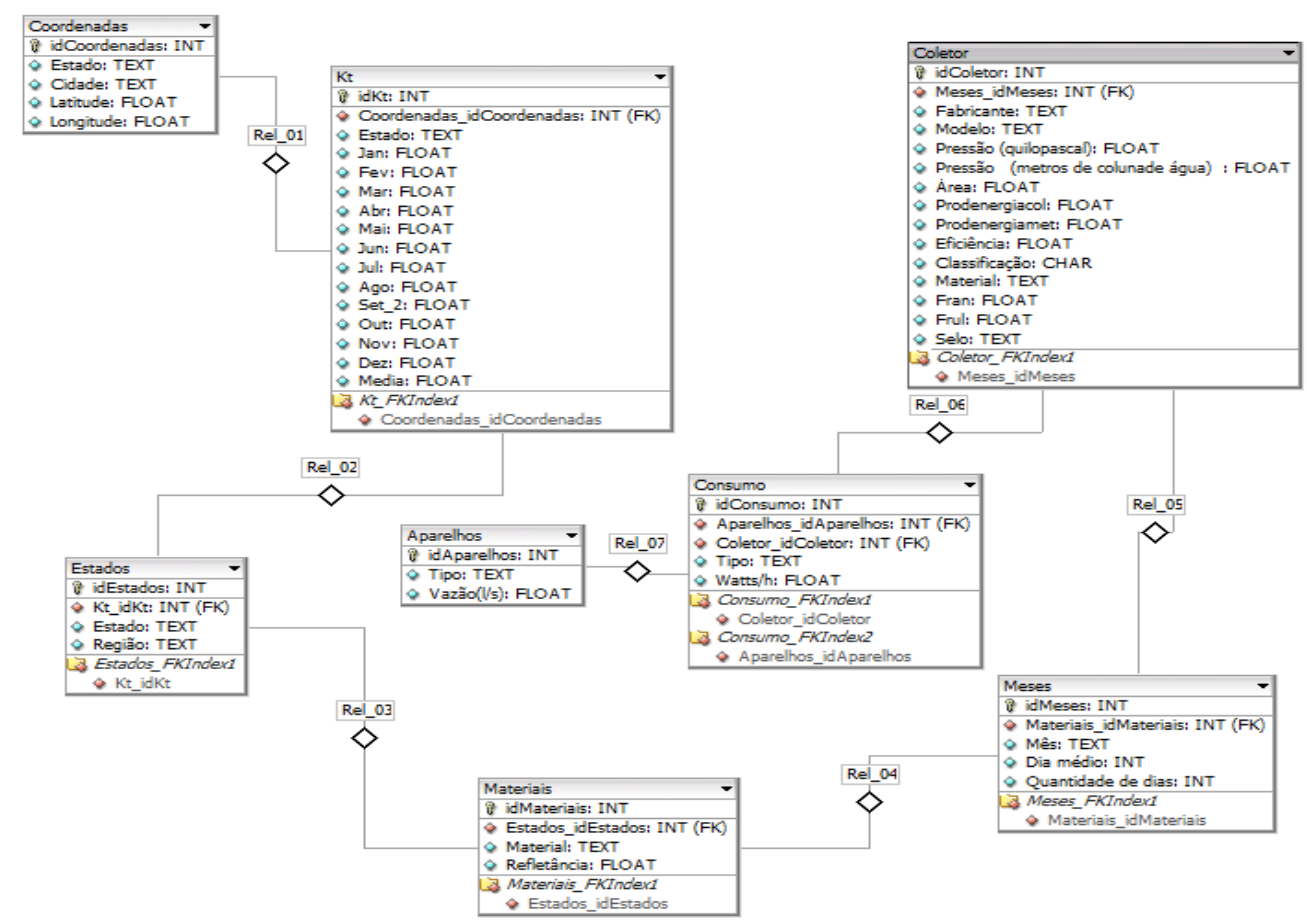

Fig. 3 Data model/entity relationship.

Table 2 Key Java system classes.

\begin{tabular}{lll}
\hline Function & Classe Java & Description \\
\hline FunctionA & Public class Calculo_A & Java class to calculate the radiation by location \\
\hline FunctionB & Public class Calculo_B & Java class for calculating the number of reservoirs \\
\hline FunctionC & Public class C_Utill & Java class energy calculation gives availability \\
\hline FunctionD & Public class Conv_D & Java class to calculate the feasibility of the project \\
\hline FunctionE & Public class Reser_E & Java class to compare the performance of collectors \\
\hline
\end{tabular}




\section{Tests and Results}

\subsection{Validation of the Solar Fraction Calculation}

Firstly, the current software results have attained excellent agreement with results from examples presented in Ref. [8].

The software validation is based on a comparison between software results with those from the calculation of the solar fraction for the Student Republic Project from UFRGS, presented in Ref. [17].

The values of the various parameters of the location, installation characteristics and hot water consumption from Ref. [17] are reproduced in Table 3.

To calculate the energy demand for heating, the temperature of the public water mains was approached as $3{ }^{\circ} \mathrm{C}$ below the monthly average environmental temperature.

Table 4 and Fig. 4 show comparisons among results produced by the current software with those reproduced from Ref. [17], obtained with the f-chart method and the Termodim software.

Table 4 shows solar fractions from the current software and from Ref. [17].

From January to May the current software results were significantly above. From June to September the results were closer to those from Termodim. For the remaining months, the results were closer to the f-chart ones.

As the Termodim deals with solar radiation data generated by the Radiasol, new data were generated by the current software, now using solar radiation data produced by Radiasol. Table 5 and Fig. 5 show the new results.

By using solar radiation data generated by the Radiasol, the yearly average solar fraction produced by the current software deviates 8.6 from that calculated by the f-chart method and only $-0.2 \%$ from that of the Termodim, as shown in Table 5.

The discrepancies found are partially justified by the lack of information about some data in Ref. [17], p.ex., mains water temperature.

Table 3 Data from Ref. [17].

\begin{tabular}{ll}
\hline Location & Porto alegre \\
\hline Latitude $\left(^{\circ}\right)$ & -30.04 \\
Longitude $\left({ }^{\circ}\right)$ & 51.2 \\
Azimuthal $\left({ }^{\circ}\right)$ & 180 \\
Angle of inclination of the collectors $\left(^{\circ}\right)$ & 40 \\
Demand points & Shower \\
Number of users & 18 \\
Hot water temperature $\left({ }^{\circ} \mathrm{C}\right)$ & 38 \\
Number of baths per day & 1 \\
Average time of the bath (min) & 10 \\
Average consumption of hot water for & 7 \\
bathing (L/min) &
\end{tabular}

Table 4 Solar fractions from the current software and from Ref. [17].

\begin{tabular}{|c|c|c|c|c|c|}
\hline Month & F-Chart & Termodim & Current & Deviation C/FC (\%) & Deviation C/T (\%) \\
\hline January & 0.83 & 0.80 & 0.87 & 4.4 & 7.3 \\
\hline February & 0.81 & 0.80 & 0.88 & 8.5 & 8.9 \\
\hline March & 0.72 & 0.77 & 0.84 & 13.6 & 8.6 \\
\hline April & 0.63 & 0.69 & 0.78 & 19.3 & 11.4 \\
\hline May & 0.46 & 0.62 & 0.70 & 33.9 & 11.6 \\
\hline June & 0.36 & 0.56 & 0.53 & 32.5 & -6.0 \\
\hline July & 0.46 & 0.56 & 0.58 & 21.1 & 2.8 \\
\hline August & 0.50 & 0.59 & 0.60 & 15.8 & 1.4 \\
\hline September & 0.58 & 0.62 & 0.62 & 6.7 & 0.0 \\
\hline October & 0.72 & 0.68 & 0.78 & 7.1 & 12.9 \\
\hline November & 0.80 & 0.73 & 0.81 & 1.4 & 10.3 \\
\hline \multirow[t]{2}{*}{ December } & 0.84 & 0.77 & 0.86 & 1.3 & 10.5 \\
\hline & \multicolumn{3}{|c|}{ Average deviations } & 13.8 & 6.7 \\
\hline
\end{tabular}




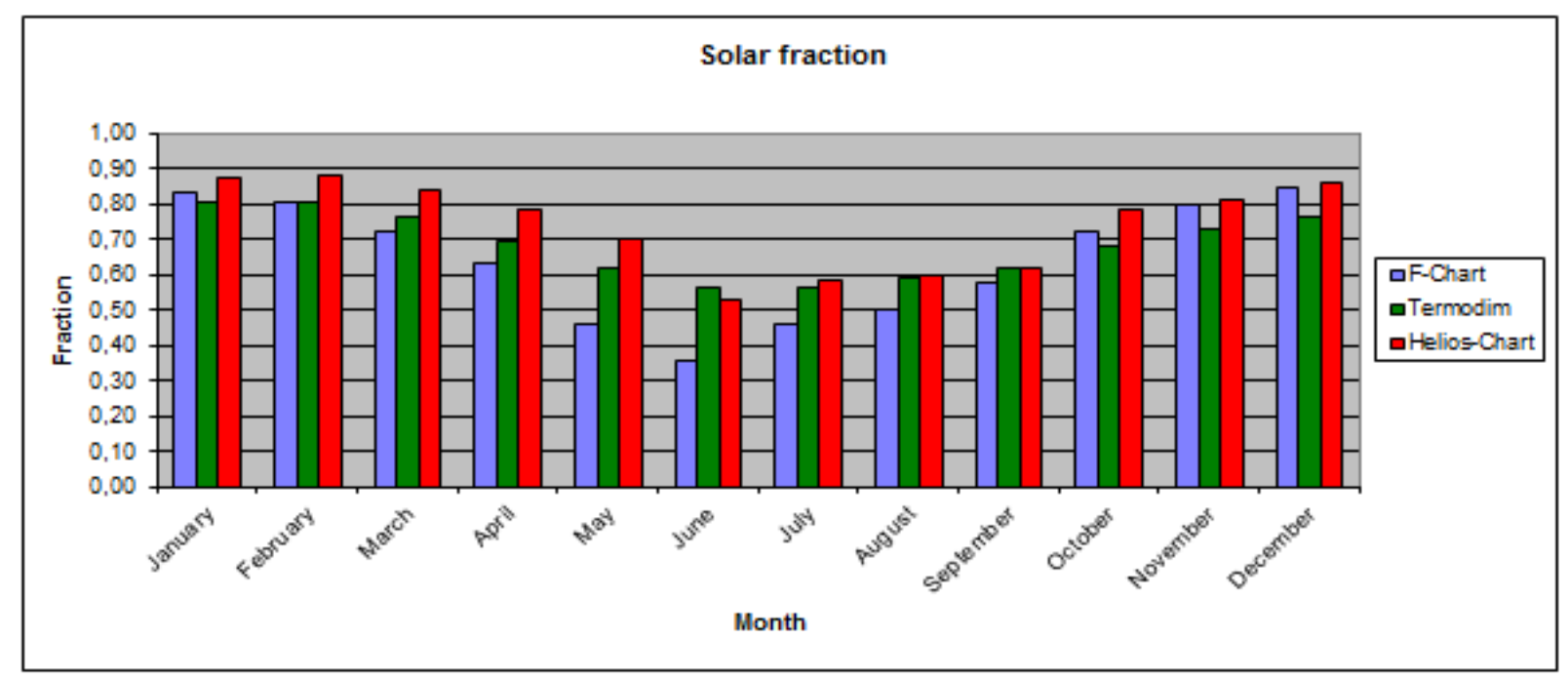

Fig. 4 Solar fractions from the current software and from Ref. [17].

Table 5 New comparison of solar fractions from the current software and from Ref. [17].

\begin{tabular}{llllrr}
\hline Month & F-Chart & Termodim & Current & Deviation C/FC (\%) & Deviation C/T (\%) \\
\hline January & 0.83 & 0.80 & 0.86 & 3.2 & 6.2 \\
February & 0.81 & 0.80 & 0.84 & 3.8 & 4.3 \\
March & 0.72 & 0.77 & 0.78 & 6.6 & 1.3 \\
April & 0.63 & 0.69 & 0.69 & 9.0 & 11.4 \\
May & 0.46 & 0.62 & 0.55 & 16.7 & -11.4 \\
June & 0.36 & 0.56 & 0.41 & 13.1 & -36.5 \\
July & 0.46 & 0.56 & 0.54 & 15.0 & -4.8 \\
August & 0.50 & 0.59 & 0.57 & 11.9 & -3.2 \\
September & 0.58 & 0.62 & 0.64 & 9.9 & 3.4 \\
October & 0.72 & 0.68 & 0.78 & 6.5 & 12.3 \\
November & 0.80 & 0.73 & 0.84 & 4.6 & 13.1 \\
December & 0.84 & 0.77 & 0.88 & 3.6 & 12.6 \\
\hline
\end{tabular}

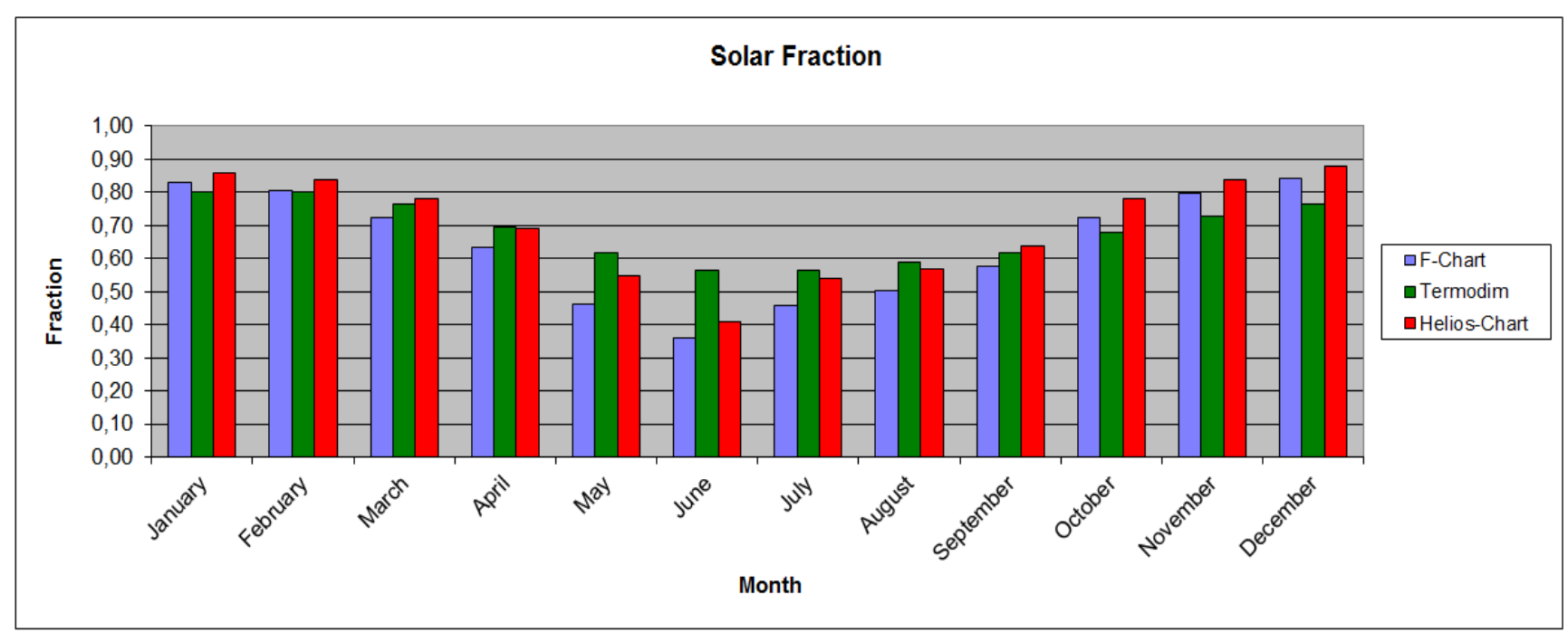

Fig. 5 New comparison of solar fractions from the current software and from Ref. [17]. 
Table 6 Comparison of results generated by the current and Radiasol software.

\begin{tabular}{|c|c|c|c|c|c|c|c|c|c|c|c|c|}
\hline \multicolumn{13}{|c|}{ Porto Alegre city } \\
\hline \multicolumn{7}{|c|}{$\mathrm{B}=40^{\circ}$} & \multicolumn{6}{|c|}{$\mathrm{Y}=180^{\circ}$} \\
\hline & January & February & March & April & May & June & July & August & September & October & November & December \\
\hline Radiasol & 19.0 & 18.4 & 17.1 & 16.0 & 13.2 & 11.1 & 13.7 & 14.3 & 15.6 & 18.3 & 19.5 & 20.2 \\
\hline Helios-chart & 18.5 & 19.1 & 18.1 & 17.4 & 15.5 & 12.8 & 13.8 & 14.0 & 14.2 & 17.4 & 17.7 & 18.6 \\
\hline $\begin{array}{l}\text { Radiasol } \\
\text { (annual } \\
\text { average) }\end{array}$ & 16.4 & 16.4 & 16.4 & 16.4 & 16.4 & 16.4 & 16.4 & 16.4 & 16.4 & 16.4 & 16.4 & 16.4 \\
\hline $\begin{array}{l}\text { Helios-chart } \\
\text { (annual } \\
\text { average) }\end{array}$ & 16.4 & 16.4 & 16.4 & 16.4 & 16.4 & 16.4 & 16.4 & 16.4 & 16.4 & 16.4 & 16.4 & 16.4 \\
\hline $\begin{array}{l}\text { Correction } \\
\text { factor }(\%)\end{array}$ & 2.3 & -3.45 & -5.66 & -8.52 & -18.04 & -14.83 & -0.24 & 1.85 & 8.78 & 4.84 & 8.85 & 7.72 \\
\hline
\end{tabular}

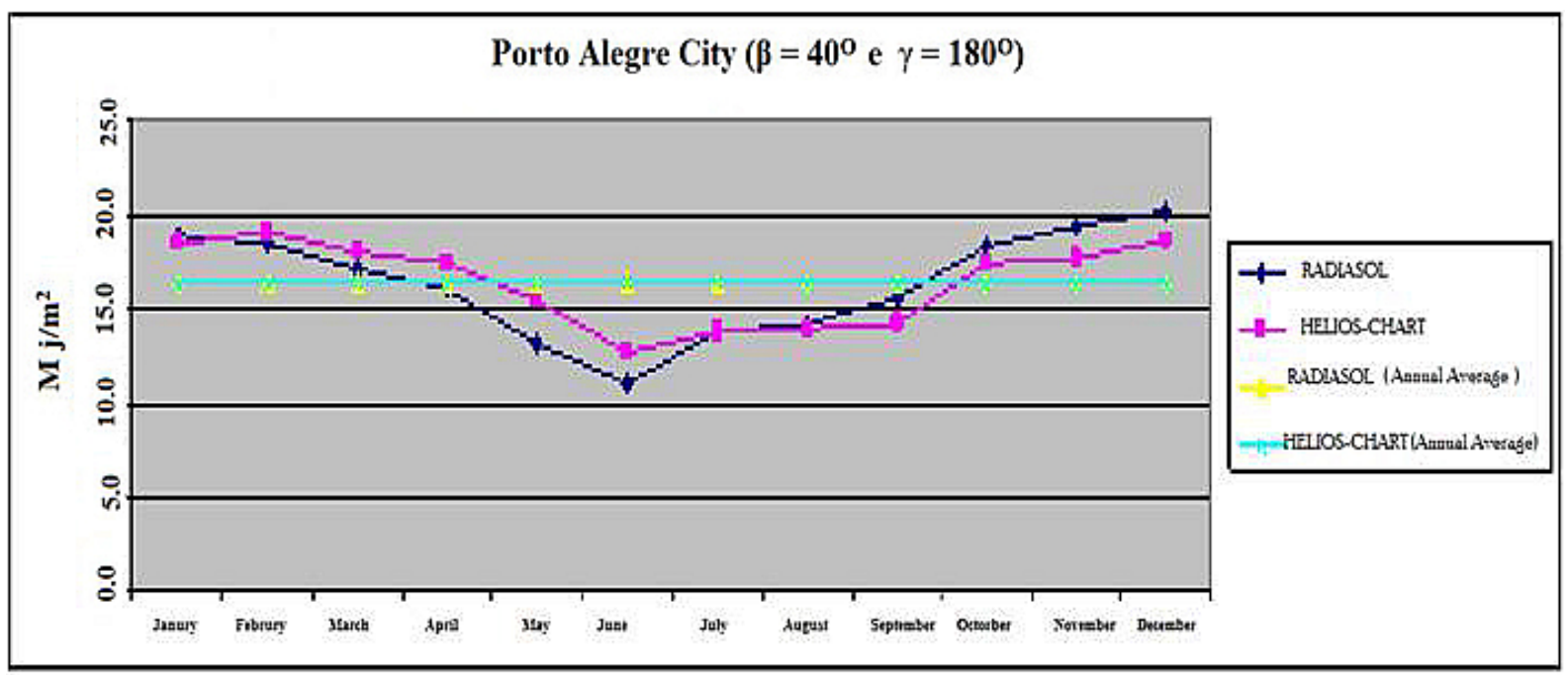

Fig. 6 Graphical comparison of results generated by the current and Radiasol software.

\subsection{Validation of the Solar Radiation Calculation}

Table 6 presents a comparison of the results generated by the software developed here and the Radiasol. Fig. 6 presents the same results in a graphical form.

From January to July, the values generated by the current software are above of those generated by Radiasol, and from August to December, the opposite occurs. In Fig. 6, it can be seen that the annual average solar radiation coincides for both programs. The highest deviation was $18 \%$ for May. These differences were expected, since the solar radiation databases used by the two programs are different.

\section{Conclusions}

The software presented here is suitable for Brazilian designers, because it uses meteorological data from the Brazilian Solarimetric Atlas and performance data published by the Brazilian Labeling Program for solar collectors and thermal reservoirs. Additionally, the software takes into account typical Brazilian domestic hot water consumption data and includes design specifications from Brazilian standards.

It is expected that the current software contributes to increase the solar water heating penetration, since it carries out both thermal and economical analysis, and the major barrier to solar energy is the lack of performance information.

The increasing availability of economical performance data will possibly let the government to make Public Policies to incentivate solar energy. It is essential to highlight here that the electrical 
showerheads receive economic incentives from the Brazilian Government.

The software can be enhanced to include environmental analysis, by calculating greenhouse gas emissions avoided along the total useful life of the solar water heating system.

In a long-term future research, it is interesting to carry out an experimental comprovation of the thermal performance predicted by this software.

\section{Acknowledgments}

This work was executed with financial support from the FINEP (Brazilian Innovation Agency), under contract number 01.07.0275.00.

\section{References}

[1] Tiba, C. 2000. Atlas Solarimétrico do Brasil-Banco de Dados Terrestres. Recife: Editora Universitária da UFPE.

[2] Helena F. Naspolini et al. 2010. Energy Conversion and Management 51: 2835-45.

[3] Helena F. Naspolini, 2011. Ricardo Rüther Solar Energy 85: 2023-32

[4] EPE, 2009. PNE (Plano Nacional de Energia)—2030. http://www.epe.gov.br.

[5] Klein, S., Cooper, P., Freeman, T., Beekman, D., Beckman, W., and Duffie, J. 1975. "A Method of Simulation of Solar Processes and Its Application." Solar Energy 17 (1): 29-37.

[6] Mohammed, M. N., Alghoul, M. A., Abulqasem, K., Mustafa, A., Glaisa, K., Ooshaksaraei, P., Yahya, M., Zaharim, A., and Sopian, K. 2011. "TRNSYS Simulation of Solar Water Heating System in Iraq." Presented at the 5th International Conference on Energy and Development-Environment-Biomedicine, Greece.

[7] Bae, C. H., Kang, K. T., Chung, J. S. 2006. "Prediction of Thermal Performance of Hot Water System with a Concentric Evacuated Tube Solar Collector Using Axially Grooved Heat Pipe." In Proceedings of the 2006 WSEAS/IASME International Conference on Heat and Mass Transfer, 50-5.

[8] Duffie, J., and Beckman, W. 2006. Solar Engineering of Thermal Processes. New York: Wiley Interscience Publication.

[9] NBR ISO 15747-2, Sistemas Solares Térmicos e Seus Componentes - Coletores Solares - Parte 2 - Metodos de Ensaio, Associação Brasileira de Normas Técnicas, Rio de Janeiro, 2009.

[10] ASHRAE STD 93, 2009. Methods of Testing to
Determine the Thermal Performance of Solar Collector. USA: American Society of Heating, Refrigerating and Air Conditioning Engineers.

[11] NBR 10185, Reservatórios Térmicos para Líquidos Destinados a Sistemas de Energia Solar - Determinação de Desempenho Térmico - Método de Ensaio, Associação Brasileira de Normas Técnicas, Rio de Janeiro, 1988.

[12] Lisboa, P. A., and Costa, M. A. F. 2012. "A Software for Performance Simulation of Solar Water Heating Systems." Presented at the 10th IASME/WSEAS International Conference on Heat Transfer, Thermal Engineering and Environment, Istanbul.

[13] Souza, A. G. L. 2011. Sistemas de Aquecimento Solar (SAS): software para projetos otimizados de sistemas de aquecimento de água mediante a utilização da energia. São Paulo: Blucher Acadêmico.

[14] Tsilingiris, P. 1996. "A Method of Simulation of Solar Processes and Its Application." Solar Energy 57 (1): 19-28.

[15] Siqueira, A. M. O. 2003. "Desenvolvimento de um Programa de Simulação Computacional de Sistemas de Aquecimento Solar para Água." Ph.D. thesis, Universidade Federal do Rio Grande do Sul.

[16] www.retscreen.net, 2005. Clean Energy Project Analysis: RETScreen Engineering \& Cases Textbook. Ministerof, Natural Resources Canada, Canadá.

[17] Kehl, F. 2004. Projeto de Um Sistema de Aquecimento Solar de Água Para República de Estudantes da UFRGS. Monografia (Trabalho de Conclusao do Curso de Engenharia Mecanica) Departamento de Engenharia Mecanica, Universidade, Federal do Rio Grande do Sul, Porto Alegre.

[18] Klein, S. A., Beckman, W. A., and Duffie, J. A. 1976. "A Design Procedure for Solar Heating Systems.” Energy 18: 113-27.

[19] Souza, A. G. L. 2009. "Desenvolvimento de Software Para Projeto de Sistemas Centralizados de Aquecimento Solar de Água." Master dissertaion, Universidade do Estado do Rio de Janeiro.

[20] Churchill, S. W., and Bernstein, M. 1977. "A Correlating Equation for Forced Convection from Gases and Liquids to a Circular Cylinder in Crossflow." Journal of Heat Transfer 99: 300-6.

[21] Holman, J. P. 1998. Transferência de Calor. NY: McGrawHill.

[22] Arruda, L. B. 2004. "Operação de Sistemas de Aquecimento Solar de Água com Controle de Vazões em Coletores Planos.” Ph.D. thesis, Universidade de São Paulo.

[23] Lisboa, P. A. 2012. "Programa de Simulação de Sistemas de Aquecimento Solar." Master dissertation, Universidade do Estado do Rio de Janeiro. 